Federal Reserve Bank of Minneapolis

Research Department

\title{
A Game-Theoretic View of the Fiscal Theory of the Price Level
}

\author{
Marco Bassetto \\ Working Paper 612
}

March 2001

\begin{abstract}
The goal of this paper is to probe the validity of the fiscal theory of the price level by modeling explicitly the market structure in which households and the governments make their decisions. I describe the economy as a game, and I am thus able to state precisely the consequences of actions that are out of the equilibrium path. I show that there exist government strategies that lead to a version of the fiscal theory, in which the price level is determined by fiscal variables alone. However, these strategies are more complex than the simple budgetary rules usually associated with the fiscal theory, and the government budget constraint cannot be merely viewed as an equilibrium condition.
\end{abstract}

*Bassetto, University of Minnesota and Federal Reserve Bank of Minneapolis. I am indebted to V. V. Chari, Lawrence Christiano, Harold Cole, Larry Jones, Narayana Kocherlakota, Christopher Pehlan, Thomas Sargent and participants at several seminars and conferences for helpful comments and discussions. The views expressed herein are those of the author and not necessarily those of the Federal Reserve Bank of Minneapolis or the Federal Reserve System. 


\section{Introduction}

The determination of the price level and inflation has long been a central concern for macroeconomists. This reflects the widespread view that the control of inflation is important for economic welfare. In view of its central importance, it is perhaps surprising that the basic determinants of the price level and inflation continue to be under dispute. Recently, this dispute has become more heated with the arrival of the "fiscal theory of the price level". The traditional, monetarist view has highlighted the importance of an independent central bank and has held that high inflation can only be ultimately fuelled by high rates of money growth. In this view, the fiscal policy is important, but mainly so because excessive deficits may eventually force the central bank to monetize. ${ }^{1}$ According to the fiscal theory, the government can instead target directly the price level using fiscal variables alone, such as the present value of future surpluses and the current level of nominal debt. The role of money is so minor that it is sometimes neglected altogether. $^{2}$

The key difference between the fiscal theory and the traditional view lies in the interpretation of the government budget constraint, which links the real value of debt to the present value of primary surpluses the government will run in the future. The advocates of the theory view this link as an equilibrium condition: an imbalance between the real value of debt and the surpluses would trigger changes in the price level that would lead back towards an equilibrium, either by reducing or by increasing the value of the nominal debt. The traditional view interprets the link as a constraint on policy, which forces government action, either through a fiscal adjustment or through a default on debt or through money-induced inflation, whenever the real value of debt

\footnotetext{
${ }^{1}$ Milton Friedman stressed extensively that inflation is chiefly a monetary phenomenon and that price stability can be achieved by stabilizing the money supply, as in Friedman and Schwartz [8]. Sargent and Wallace [17] showed that monetary and fiscal policy are intertwined through the government budget constraint, and Sargent [16] used this idea to explain several inflationary episodes.

${ }^{2}$ To my knowledge, Leeper [12] started this line of research, and Sims [20] and Woodford [22] are the seminal contributions. Woodford has developed the idea further in [23, 24, 26, 25]. Cochrane [6] has extended the analysis to long-term debt, and Dupor [7] to the exchange-rate determination in an open-economy framework. Loyo [13] has applied the theory to study inflation episodes in Brazil.
} 
and the present value of primary surpluses tend not to be equal. It is this difference that has spurred the major controversy. ${ }^{3}$

The goal of this paper is to reach a clearer and less controversial understanding of the constraints imposed on monetary and fiscal policy by their interdependence. I show that the standard definitions of a competitive equilibrium and/or of a commitment equilibrium only characterize equilibrium paths, ${ }^{4}$ and do not provide a full description of the economy that is needed to address the issues raised by the fiscal theory. I describe the entire economy as a game, and I provide a market microstructure that shows how prices arise from the actions of the players in the economy. Specifically, prices are formed by the bidding process of households and the government on specialized trading posts where goods and assets are traded pairwise. While the market structure I describe is highly stylized, it is able to clearly set apart constraints on the set of actions that the government can take from relations that hold only in equilibrium, thereby shedding light on the key source of controversy.

I show that, in the environment I describe, there exist government strategies that lead to a version of the fiscal theory, in which the price level is determined by fiscal variables alone. However, these strategies are more complex than the simple budgetary rules usually associated with the fiscal theory, and the government budget constraint cannot be merely viewed as an equilibrium condition.

Spelling out completely the assumptions on the government strategy that lead to a fiscal theory of the price level is very important for policy advice. Previous papers on the subject claimed that price stability could be achieved by a firm commitment by the government to pursue a policy of exogenous and fixed surpluses/deficits. The appropriate policy called thus for enhancing the credibility of the commitment to a future fiscal policy. Sufficient credibility would rule out the possibility of any debt crisis occurring; if a crisis ever occurred, the government should simply be committed to ignore it and not pursue any fiscal adjustment. This paper shows

\footnotetext{
${ }^{3}$ Among the authors that have attacked the view that the government budget constraint is purely an equilibrium condition is Buiter [2]. Other papers that express similar views are by McCallum [14] and Kocherlakota and Phelan [11].

${ }^{4}$ I address this issue in a more general setting in Bassetto [1].
} 
that in a debt crisis a fiscal adjustment is forced onto the government: not enough resources would be available to pursue the original plan. The appropriate advice for achieving price determinacy through the fiscal side of the economy is a much more painful recipe: it calls for more taxes during the crisis without any tax cut ever. A credible commitment to such a strategy would deliver an above-market rate of return to government lenders in the event of a debt crisis, thereby making expectations of a crisis self-defeating. Both the ability to commit to such a strategy and the credibility of such a commitment might be much more problematic than what is needed for the policy rule advocated by previous papers.

Section 2 illustrates the fiscal theory of the price level and the theoretical criticism against it. Section 3 describes the market structure I assume. Section 4 contains the main results of the paper, section 5 extends the results to an infinite-horizon environment, section 6 briefly discusses the introduction of money and section 7 concludes.

\section{Ricardian and non-Ricardian Policy Rules}

In this paper, I study a cashless economy, in which money is purely a unit of account. This specification is often pursued by the papers that adopt the fiscal theory of the price level, consistently with their idea that money as a medium of exchange is secondary in determining the price level. ${ }^{5}$

I choose a cashless specification because it is simpler and still captures the main insights of the debate. I briefly discuss the role of money and its interaction with the results presented here in section 6 .

Let us consider an economy with a continuum of identical households that live for two periods (1 and 2) and a government. Households receive a constant exogenous endowment of a single homogeneous good in each period, which we normalize to $1 .^{6}$ Each household starts the first

\footnotetext{
${ }^{5}$ See e.g. Woodford [25] and Cochrane [6].

${ }^{6} \mathrm{~A}$ nonconstant endowment and production could be easily introduced without altering the results, but they would make the notation more cumbersome and would introduce many more markets to keep track of in the game-theoretic version.
} 
period with $B_{1}$ units of government bonds. A government bond is a claim to 1 "dollar", which is just a unit of account. All debt is assumed to mature in one period; once again, this is not an important assumption, but saves on notation considerably. The government has access to lump-sum taxes in both periods; with the tax revenues $T_{1}$ and $T_{2}$, it finances some exogenous government spending in either period $\left(G_{1}\right.$ and $\left.G_{2}\right)$, as well as repayment of its original debt. We assume no uncertainty.

Households have preferences given by

$$
u\left(c_{1}\right)+u\left(c_{2}\right)
$$

where $c_{j}$ is consumption in period $j$ and $u$ is strictly increasing, concave and continuously differentiable. We use lower-case letters for variables that refer to a single household, and upper-case letters for the corresponding aggregates. All competitive equilibria of this economy will be symmetric, i.e., each household will take the same actions; therefore, lower-case and upper-case variables will always coincide in equilibrium. ${ }^{7}$

Government spending does not enter in the households' utility; as usual, it could be added in a strongly separable way without affecting the results.

The household's flow budget constraints are

$$
\begin{aligned}
& P_{1} c_{1} \leq P_{1}\left(1-T_{1}\right)+B_{1}-\frac{b_{2}^{d}}{R_{1}} \\
& P_{2} c_{2} \leq P_{2}\left(1-T_{2}\right)+b_{2}^{d}
\end{aligned}
$$

$P_{j}$ is the price level, i.e., the inverse of the value of a dollar; $R_{1}$ is the nominal interest rate in the economy and $b_{2}^{d}$ is the amount of newly-issued government bonds with period-2 maturity that the household demands in period 1.

\footnotetext{
${ }^{7}$ Since (1) is strictly concave and the constraint set is convex, there will be a unique solution to the maximization problem, which is why all households in equilibrium will take the same action.
} 
The government budget constraint for this economy is ${ }^{8}$

$$
\begin{aligned}
& P_{1} G_{1}=P_{1} T_{1}+\frac{B_{2}}{R_{1}}-B_{1} \\
& P_{2} G_{2}=P_{2} T_{2}-B_{2}
\end{aligned}
$$

where $B_{2}$ is the supply of bonds in period 2 .

A competitive equilibrium is an allocation $\left(C_{1}, C_{2}, B_{2}^{D}\right)$, a price system $\left(P_{1}, P_{2}, R_{1}\right)$ and a government policy $\left(T_{1}, T_{2}, B_{2}\right)$ such that:

(i) given the price system and the government policy, the allocation maximizes the households' utility subject to the budget constraint 2 ;

(ii) the government budget constraint (3) is satisfied;

(iii) Markets clear, i.e. $B_{2}^{D}=B_{2}$.

The definition of a competitive equilibrium describes the actions taken by the households and the government at the equilibrium; it does not specify what would happen if the government took a different policy, or if the price system were different from the equilibrium one.

We define a fiscal policy rule as a mapping from the price $P_{1}$ into $T_{1}$, and from the vector $\left(P_{1}, P_{2}\right)$ to $T_{2}$. While this economy does not have money, we still define a monetary policy rule as a mapping from the price $P_{1}$ to an interest rate $R_{1}$. The rationale behind this definition is the perception that the cashless economy is only a limiting concept and that the central bank retains the ability to peg the nominal interest rate as we drive the economy to the cashless limit. In the game we describe below, the ability of the government to peg the interest rate will explicitly come out of the model. ${ }^{9}$

We define a policy rule to be the combination of a fiscal and monetary policy rule.

\footnotetext{
${ }^{8}$ In what follows, I do not allow the government to waste any resources (other than spending itself...). The analysis would be similar if the government had access to free disposal; in that case, violations of (3) would only be a problem when taxes are too small.

${ }^{9}$ The definition of a fiscal and monetary policy rule here is more limited than the one in Woodford [22, 23] or in Kocherlakota and Phelan [11], as I specify which variables the government is targeting in its rule. This is only done for simplicity of exposition.
} 
The literature distinguishes two types of rules, which I will call Ricardian and non-Ricardian, following Woodford [23]. A policy rule is Ricardian if it satisfies the government budget constraint for any price vector; it is non-Ricardian otherwise.

Proponents of the fiscal theory of the price level assume that the government can commit to non-Ricardian rules. While their arguments are not cast in a model that properly specifies out of equilibrium behavior, their reasoning is (a variation of) the following. For any price $P_{1}$, tax $T_{1}$ and interest rate $R_{2}>0$, it is possible to find a supply of government debt $B_{2}$ such that the flow budget constraint is satisfied in period 1. If the policy rule is non-Ricardian, then there are some price vectors $\left(P_{1}, P_{2}\right)$ for which the budget constraint in period 2 is not satisfied; at this price vector, the government would "offer" bonds $B_{3}$ that mature after the end of the economy to meet its flow budget constraint. Since nobody is willing to buy these bonds, there is excess supply and prices will have to adjust.

The opponents of the fiscal theory ${ }^{10}$ insist that any rule that is non-Ricardian is simply a misspecification: no matter what the prices are, the government should always choose a policy that satisfies its intertemporal budget constraint, which includes the transversality condition $B_{3}=0$.

In order to deem non-Ricardian rules admissible, it is necessary to interpret the intertemporal budget constraints differently: the households' budget constraints are viewed as binding in all contingencies, whereas the government budget constraint is interpreted as a "government valuation equation" that only holds at the equilibrium price (see e.g. Cochrane [5]). Woodford [26] justifies this asymmetry with two arguments:

(i) if the households were not subject to budget constraints, they would demand an infinite amount of goods, so there would be no equilibrium; the same is not true for the government, which (for exogenous reasons) has an interior satiation point;

(ii) households are price takers, whereas the government is a big player capable of moving prices.

\footnotetext{
${ }^{10}$ See e.g. Buiter [2], Kocherlakota and Phelan [11].
} 
Neither of these arguments is compelling. The possibility or impossibility of violating the budget constraint out of equilibrium should not have anything to do with preferences. Having the ability to affect prices is not the same as having the ability of violating a budget constraint for any given price vector.

A different argument that is sometimes used in justifying the fiscal theory of the price level envisions a game between the government and the "Walrasian auctioneer", whose goal is to achieve market clearing. Under a non-Ricardian rule, the government moves before the "Walrasian auctioneer" does, ${ }^{11}$ so that the auctioneer is forced to call prices that are consistent with the real surpluses announced by the government. Since the Walrasian auctioneer is purely a reduced form for a more complex price formation mechanism, it is impossible to evaluate within such framework who should play the first move, and little progress can be achieved in understanding whether a non-Ricardian policy rule can be truly adopted by the government.

The admissibility of non-Ricardian rules has dramatic implications on the determinacy of the price level, which we now turn to.

Proposition 1 If the government adopts a Ricardian policy rule, $P_{1}$ is indeterminate; more precisely, given any strictly positive value, there exists a competitive equilibrium in which $P_{1}$ attains that value.

Proof. Under a given policy rule, a (symmetric) competitive equilibrium is characterized by the following equations:

(i) first-order conditions for the household's problem

$$
u^{\prime}\left(C_{1}\right)=\frac{P_{1} R_{1}}{P_{2}} u^{\prime}\left(C_{2}\right)
$$

(ii) household budget constraints at equality

$$
\begin{aligned}
& P_{1} C_{1}=P_{1}\left(1-T_{1}\right)+B_{1}-\frac{B_{2}^{d}}{R_{1}} \\
& P_{2} C_{2}=P_{2}\left(1-T_{2}\right)+B_{2}^{d}
\end{aligned}
$$

\footnotetext{
${ }^{11}$ See e.g. Christiano and Fitzgerald [4]. While Christiano and Fitzgerald seem to accept the validity of the fiscal theory of the price level on theoretical grounds, they challenge the assumption that it correctly represents actual government behavior.
} 
(iii) government budget constraints (at equality) (3)

(iv) market clearing conditions

$$
\begin{aligned}
& C_{1}=1-G_{1} \\
& C_{2}=1-G_{2} \\
& B_{2}^{d}=B_{2}
\end{aligned}
$$

(v) policy rule specification: $T_{1}=T_{1}\left(P_{1}\right), R_{1}=R_{1}\left(P_{1}\right)$ and $T_{2}=T_{2}\left(P_{1}, P_{2}\right)$.

Let $\bar{P}_{1}$ be a strictly positive value. We show that, if the policy rule is Ricardian, there exists a competitive equilibrium in which $P_{1}=\bar{P}_{1}$. Given $\bar{P}_{1}$, the policy rule specifies a unique value for $T_{1}$ and $R_{1}$. We can substitute these values to obtain a unique value for the supply of bonds $B_{2}$ from the government budget constraint. Consumption and the demand for bonds can be uniquely determined by the market clearing conditions; these choices satisfy the household budget constraint in period 1 by Walras' law, as can be verified by substitution. The price level in the second period is determined by (4): even though the government cannot set the initial price level, it controls inflation through the choice of the nominal interest rate. If the policy rule is Ricardian, $T_{2}\left(P_{1}, P_{2}\right)$ is consistent with the period-2 budget constraint of the government; finally, the household budget constraint in period 2 is redundant because of Walras' law. QED.

Proposition 1 is the cashless counterpart to the well-known result that, in many monetary models, nominal interest-rate targeting leads to price indeterminacy.

While in a Ricardian regime the fiscal policy cannot help in determining the initial price level, the result obviously changes when we no longer require $T_{2}\left(P_{1}, P_{2}\right)$ to be such that the government budget constraint is met at all prices. The fiscal theory of the price level is most often derived by assuming that the government sets the real value of taxes $T_{1}$ and $T_{2}$ and the nominal interest rate $R_{1}$ independently of the prices.

Proposition 2 Assume that the policy rule specifies unconditional values for $T_{1}, T_{2}$ and $R_{1}$ and that $B_{1}>0$. There exists at most one competitive equilibrium that is consistent with such a rule; the equilibrium exists provided $T_{1}$ or $T_{2}$ are sufficiently large. 
Proof. A competitive equilibrium must satisfy the same equations we listed in proposition (1). As before, we can uniquely determine consumption from the market clearing conditions. We can solve (3) and (4) as a system of 3 equations in $P_{1}, P_{2}$ and $B_{2}$, which yields the following unique result:

$$
\begin{aligned}
P_{1} & =\frac{B_{1}}{\left(T_{1}-G_{1}\right)+\left(T_{2}-G_{2}\right) \frac{u^{\prime}\left(C_{2}\right)}{u^{\prime}\left(C_{1}\right)}} \\
P_{2} & =\frac{B_{1} R_{1}}{\left(T_{1}-G_{1}\right) \frac{u^{\prime}\left(C_{1}\right)}{u^{\prime}\left(C_{2}\right)}+\left(T_{2}-G_{2}\right)} \\
B_{2} & =\frac{B_{1} R_{1}\left(T_{2}-G_{2}\right)}{\left(T_{1}-G_{1}\right) \frac{u^{\prime}\left(C_{1}\right)}{u^{\prime}\left(C_{2}\right)}+\left(T_{2}-G_{2}\right)}
\end{aligned}
$$

This system yields positive prices $P_{1}$ and $P_{2}$ if $T_{1}$ or $T_{2}$ are large enough. Finally, market clearing implies that $B_{2}^{d}=B_{2}$, and the household's budget constraints are satisfied by Walras' law. QED.

The policy rule described in proposition 2 is consistent with a competitive equilibrium only if the initial real value of debt takes a particular value. This is the source of the fiscal theory of the price level: if taxes do not respond to meet the government budget constraint, then the price level must do so to guarantee that the real value of debt acts as the residual variable. Taxes must not be too low, for otherwise they would require a negative real value of debt, which is ruled out (assuming $B_{1}>0$ ) as prices must be positive.

The fiscal theory of the price level follows from the assumption that the policy rule in proposition 2 (or variants of it, as in Loyo [13], where the interest rate reacts to inflation) is a good description of the actual policy rule followed in many countries. Accordingly, the papers that advocate the fiscal theory view the price level as being primarily determined by the dynamics of government deficits (surpluses) and debt.

Both the papers that advocate the fiscal theory and those who deny its possibility or plausibility contain discussions of policy rules and often vague descriptions of out-of-equilibrium dynamics and adjustment to the equilibrium. However, all of these papers define an equilibrium as a competitive equilibrium, which is not a good concept to address the consequences of deviations from the equilibrium path.

To my knowledge, no paper has attempted to cast the problem in an environment in which it is possible to explicitly discuss the household and government behavior in all contingencies. 
By writing the economy as a game, I am able to answer explicitly the following questions: is it possible for the government to commit to non-Ricardian policy rules? Can price determinacy be achieved through the fiscal policy when the monetary policy is characterized by interest-rate targeting? What actions lead to out-of-equilibrium prices, and what would be the evolution of the economy out of equilibrium?

\section{A Game-Theoretic Version of the Economy}

In order to model the economy we described above as a game, we need to be explicit about the way prices are formed from the actions by the households and the government. In what follows, I model the market structure as a version of trading posts that is similar to Shubik [19]. ${ }^{12}$ While I make a number of assumptions on the details of how trading takes place, it is straightforward to show that these details could be changed without affecting the results. What can potentially make a difference is the main assumption that trading takes place simultaneously and through trading posts. ${ }^{13}$

The players of the game are households and the government. Every time a player wishes to trade, it has to submit a bid to a specialized trading post, which I will equivalently call a "market". Each market deals with a pair of goods or assets, and there is a market for any exchange that the government and the households may wish to entertain. Accordingly, in period 1 there are 3 trading posts: in the first, goods are exchanged for maturing bonds; in the second, goods are exchanged for newly issued bonds that mature in period 2; in the third, maturing bonds can be exchanged for newly issued bonds that mature in period 2. In period 2, the only trading post is one where goods are exchanged for maturing bonds.

\footnotetext{
${ }^{12}$ I assume enough symmetry that these trading rules yield the Walrasian outcome. As Shubik [19] points out, this is far from guaranteed in general. A more-complicated version with multilateral trading posts could overcome this problem.

${ }^{13}$ An alternative model of the microstructure of the determination of prices in a competitive equilibrium is provided by the search-theoretic approach developed by Rubinstein and Wolinsky [15] and Gale [9, 10]. However, this approach is considerably more cumbersome to deal with, and introducing a government in their environment would require significant adaptations that are currently beyond the scope of this project.
} 
As in Shubik [19], each household that wants to trade must submit an unconditional bid for the amount it wishes to sell on a given market. The bid must represent a quantity of the good (or bond) sold, rather than bought, because only in this way households can meet their binding obligation at any price. In equilibrium, households have perfect foresight about the relative price in each market, and a single household cannot alter any price through its actions. For this reason, households would be strictly indifferent between using unconditional bids or more-sophisticated bid schemes.

In some of the markets, the government has more degrees of freedom in submitting bids than the households do: as a seller of future bonds, the government is not constrained by a limited endowment, as it can freely print as many bonds as it wishes. For this reason, in such markets the government can either submit a sale bid for a specific quantity, or set a price at which it is ready to meet any demand. I assume that the government submits unconditional sale bids in all markets except the one where maturing bonds are exchanged for newly-issued bonds, in which the government sets the price. This assumption retains the analogy with the previous section in which the government targeted interest rates. The results I establish are independent of this assumption.

Being a large player, the government could potentially have an interest in submitting morecomplex bids than just setting a price or a quantity offered. As an example, it could submit complicated bids, in which rationing is sometimes involved. However, I show that the government can attain price determinacy even by using the simple bidding scheme proposed above, so nothing would be gained if the government were to resort to more-complicated mechanisms.

Each trading post (except the one that determines the nominal interest rate) clears simply by setting the price equal to the ratio of the supply of the two objects to be exchanged; at that price, market clearing is achieved as an identity, independently of the bids, and exchange takes place.

As in the previous section, lower-case variables refer to single households and upper-case variables refer to aggregates.

The timing of the economy is as follows. 
(i) Households start with 1 unit of the period- 1 good and $B_{1}$ units of government debt maturing in period 1. The government levies a first installment of period-1 taxes, $T_{1}^{1} \in[0,1]$ and sets a price $P_{B_{1} B_{2}}$ at which it stands ready to exchange maturing bonds for new bonds. From here on, I index prices by the objects that are being exchanged at each trading post. The government submits a sale bid for $C_{1}^{B_{1}}$ units of goods in the market for maturing bonds, subject to $C_{1}^{B_{1}} \leq T_{1}^{1}$. It also submits a sale bid for $B_{2}^{C_{1}}$ units of new bonds in exchange for goods. ${ }^{14}$ I use superscripts to indicate the object each player wishes to buy in a market: e.g., $C_{1}$ represents period- 1 goods, $B_{1}$ represents bonds maturing in period 1.

(ii) Trading opens. There are bilateral trading posts for each possible exchange; in our case 3 exchanges are possible: goods for maturing government bonds, goods for new bonds issued by the government and maturing bonds for new bonds. Each household may submit a sale bid for $b_{1}^{C_{1}}$ units of bonds in the market for goods, and another sale bid for $b_{1}^{B_{2}}$ units of bonds in the market for new bonds maturing next period, subject to the constraint that $b_{1}^{C_{1}}+b_{1}^{B_{2}} \leq b_{1} \equiv B_{1}$, i.e., the sale bids cannot exceed the total amount of bonds the household starts with. Each household may also submit a sale bid of $c_{1}^{B_{2}}$ units of goods in exchange for new bonds, subject to the constraint that $c_{1}^{B_{2}} \leq 1-T_{1}^{1}$.

(iii) For the markets in which the price is not set by the government, the ratio of the quantities of the unconditional bids sets the price and exchange takes place. The government meets the demand of new bonds in the market in which it sets the price. We thus have

$$
\begin{aligned}
P_{C_{1} B_{1}} & =\frac{B_{1}^{C_{1}}}{C_{1}^{B_{1}}} \\
P_{C_{1} B_{2}} & =\frac{B_{2}^{C_{1}}}{C_{1}^{B_{2}}} \\
B_{2}^{B_{1}} & =B_{1}^{B_{2}} P_{B_{1} B_{2}}
\end{aligned}
$$

The relative price of goods and maturing bonds $P_{C_{1} B_{1}}$ determines the value of the unit of account (the "dollar") for the cashless economy. For this reason, I interpret $P_{C_{1} B_{1}}$ as

\footnotetext{
${ }^{14}$ While we assume here that the government submits its bids first, nothing would change if we assumed that the bids are submitted jointly by the government and the households; this is true because we only look at equilibria in which the government specifies its strategy ex ante.
} 
the general level of prices; it thus corresponds to $P_{1}$ as defined in section 2. $P_{B_{1} B_{2}}$ is the relative price of the unit of account in the two periods, i.e., it is the nominal interest rate in the economy, which we called $R_{1}$ in the previous section. Here and throughout the rest of the paper, prices are not defined on markets in which either side contains no bids; any positive bid on a market where no bids are posted on the other side is wasted.

(iv) The government levies a second installment of taxes (or transfers) $T_{1}^{2} \in\left[-T_{1}^{1}+C_{1}^{B_{1}}-\right.$ $\left.C_{1}^{B_{2}}, 1-T_{1}^{1}+C_{1}^{B_{1}}-C_{1}^{B_{2}}\right]$. The bounds ensure that the government has enough resources to carry out the transfer or the households have enough resources in the aggregate to meet the tax obligation. If an individual household bids more than the others, it might not have enough resources to meet the tax obligation at this stage. We assume that the government can inflict an arbitrarily negative punishment to any household that is unable to meet its tax obligations, so it is always optimal for a household to plan to have enough resources left to pay for taxes. ${ }^{15}$ Any unmet tax obligation is distributed evenly across remaining households. ${ }^{16}$

(v) Consumption and government spending take place. Each household consumes

$$
c_{1}=\max \left\{0,1-T_{1}-c_{1}^{B_{2}}+\frac{b_{1}^{C_{1}}}{P_{C_{1} B_{1}}}\right\}
$$

where $T_{1}=T_{1}^{1}+T_{1}^{2}$ and starts period 2 with $b_{2}=b_{1}^{B_{2}} P_{B_{1} B_{2}}+c_{1}^{B_{2}} P_{C_{1} B_{2}}$ units of nominal bonds. The government spends

$$
G_{1}=T_{1}+C_{1}^{B_{2}}-C_{1}^{B_{1}}
$$

units in the first period.

(vi) Households start with 1 unit of the period-2 good. The government levies a lump-sum tax $T_{2} \in[0,1]$. In the second period, we do not distinguish between a first and a second installment in taxes, although we could do so. In the last period, the government cannot raise

\footnotetext{
${ }^{15}$ If $\lim _{c \rightarrow 0} u(c)=-\infty$ and $T_{1}^{2}<1-T_{1}^{1}+C_{1}^{B_{1}}-C_{1}^{B_{2}}$, a sufficient punishment is for the government to tax away any residual endowment the household has in that period.

${ }^{16}$ The bounds on $T_{1}^{2}$ guarantee that there will be enough resources to be raised even if they are not evenly spread in the population, so that the government strategy is feasible in all contingencies.
} 
any resources by borrowing and hence cannot face an unexpected shortfall in its resources; as a consequence, distinguishing between a first and second installment is superfluous. The only market open in period 2 is the one where maturing bonds are traded for goods. The government submits a bid $C_{2}^{B_{2}} \leq T_{2}-G_{2}$.

(vii) Each household submits a bid $b_{2}^{C_{2}} \leq b_{2}$.

(viii) The price is determined as before by the ratio of bids, i.e.

$$
P_{C_{2} B_{2}}=\frac{B_{2}^{C_{2}}}{C_{2}^{B_{2}}}
$$

(ix) Each household consumes

$$
c_{2}=1-T_{2}+\frac{b_{2}^{C_{2}}}{P_{C_{2} B_{2}}}
$$

The government spends

$$
G_{2}=T_{2}-C_{2}^{B_{2}}
$$

The household's preferences over the outcomes are described by (1). As for the government, the papers that address the fiscal theory of the price level do not model its preferences explicitly. Since I am interested in what the government can do rather than what the optimal government policy is, I also take the policy as exogenous and look for strategies that let the government achieve an exogenous "target" level of taxes $\bar{T}$ in both periods. ${ }^{17}$

The fiscal theory is often associated with the notion that the government is able to "commit" to its policies ex ante. My game is consistent with this interpretation, although it does not require it. However, commitment should be modelled as an additional stage at the beginning of the game, as in Schelling [18]. In this stage, the government picks (commits to) the strategy it will follow throughout the rest of the game. After this initial stage, the government's actions are entirely determined by the strategy chosen ex ante, so that in the subgame that ensues only the households are players. In related work (Bassetto [1]), I contrast this definition of commitment

\footnotetext{
${ }^{17}$ In a world of distortionary taxes, the fiscal theory can be combined with standard public-finance arguments to provide a case for tax smoothing through the effects of the price level on the value of nominal debt; see e.g. Woodford [26]. The assumption of a constant target can be easily relaxed without affecting any of the results.
} 
to that contained in Chari or Kehoe [3] and Stokey [21], in which the timing of the game is changed so that the government can simply commit to actions, rather than strategies. The main results we obtain below hinge on the fact that some government actions are impossible under some contingencies: e.g., it is impossible for the government to spend more resources than it has. The definition I adopt here takes into account these physical restrictions that even a government with full commitment power faces.

Definition 1 A symmetric competitive equilibrium ${ }^{18}$ is an allocation

$$
\left(C_{1}, C_{2}, T_{1}^{1}, T_{1}^{2}, T_{2}, B_{2}, B_{1}^{C_{1}}, B_{1}^{B_{2}}, C_{1}^{B_{2}}, B_{2}^{C_{2}}, C_{1}^{B_{1}}, B_{2}^{B_{1}}, B_{2}^{C_{1}}, C_{2}^{B_{2}}\right)
$$

and a price system

$$
\left(P_{C_{1} B_{1}}, P_{B_{1} B_{2}}, P_{C_{1} B_{2}}, P_{C_{2} B_{2}}\right)
$$

such that:

(i) Given the price system and taxes $\left(T_{1}^{1}, T_{1}^{2}, T_{2}\right),\left(C_{1}, C_{2}, B_{2}, B_{1}^{C_{1}}, B_{1}^{B_{2}}, C_{1}^{B_{2}}, B_{2}^{C_{2}}\right)$ solves the household maximization problem:

$$
\begin{array}{rl}
\max _{c_{1}, c_{2}, b_{2}, b_{1}^{C_{1}}, b_{1}^{B_{2}}, c_{1}^{B_{2}}, b_{2}^{C_{2}} \in \mathbb{R}_{+}^{7}} & u\left(c_{1}\right)+u\left(c_{2}\right) \text { s.t. } \\
c_{1} & =1-T_{1}^{1}-T_{1}^{2}+\frac{b_{1}^{C_{1}}}{P_{C_{1} B_{1}}}-c_{1}^{B_{1}} \\
c_{2} & =1-T_{2}+\frac{b_{2}^{C_{2}}}{P_{C_{2} B_{2}}} \\
b_{1}^{C_{1}}+b_{1}^{B_{2}} \leq b_{1} & \\
b_{2} & =b_{1}^{B_{2}} P_{B_{1} B_{2}}+c_{1}^{B_{2}} P_{C_{1} B_{2}} \\
b_{2}^{C_{2}} & \leq b_{2} \\
c_{1}^{B_{1}} & \leq 1-T_{1}^{1}
\end{array}
$$

\footnotetext{
${ }^{18}$ Not all competitive equilibria of this economy in the game-theoretic form will be symmetric. While all households will share the same equilibrium consumption and will start period 2 with the same amount of bonds, the economy has redundant markets, so that in principle each household could attain the same net trades through different bids in the markets. For simplicity, we restrict our attention to the case in which all bids are the same in equilibrium, but the results do not hinge on this.
} 
(ii) The government's actions satisfy the feasibility requirements

$$
\begin{gathered}
T_{1}^{1} \in[0,1] \\
C_{1}^{B_{1}} \in\left[0, T_{1}^{1}\right] \\
T_{1}^{2} \in\left[-T_{1}^{1}+C_{1}^{B_{1}}-C_{1}^{B_{2}}, 1-T_{1}^{1}+C_{1}^{B_{1}}-C_{1}^{B_{2}}\right]
\end{gathered}
$$

(iii) Markets clear and the government budget constraints hold, i.e. equations (8), (11), (10) and (13) are satisfied.

As usual, the definition of a competitive equilibrium only involves only the outcome of the game. The information a competitive equilibrium gives us is that each household would optimally choose the prescribed allocation if it expects everybody else to choose the same allocation, the government to follow the specified policy and the price system to be the one included in the definition. A competitive equilibrium does not convey any information on how the households or the government would react if people behaved differently. Compared with the definition of a competitive equilibrium in section 2 , the only difference is that we need here to specify the trade volume and the relative price in each market. The set of consumption levels $\left(C_{1}, C_{2}\right)$, prices $\left(P_{1}=P_{C_{1} B_{1}}, P_{2}=P_{C_{2} B_{2}}, R_{1}=P_{B_{1} B_{2}}\right)$, government taxes $\left(T_{1}, T_{2}\right)$ and period-2 bond holdings $B_{2}=B_{2}^{d}$ compatible with a competitive equilibrium is the same under both definitions; the latter definition only specifies more details of how trading actually takes place within the market structure assumed here.

A household strategy is the following:

1. bids $\left(b_{1}^{C_{1}}, b_{1}^{B_{2}}, c_{1}^{B_{2}}\right)$ as functions of the actions taken by the government up to that node, i.e. $\left(T_{1}^{1}, P_{B_{1} B_{2}}, C_{1}^{B_{1}}, B_{2}^{C_{1}}\right)$;

2. a bid $b_{2}^{C_{2}}$ as a function of the government choices $\left(T_{1}^{1}, T_{1}^{2}, T_{2}, P_{B_{1} B_{2}}, C_{1}^{B_{1}}, B_{2}^{C_{1}}, C_{2}^{B_{2}}\right)$, of the aggregate bids by the households in period $1\left(B_{1}^{C_{1}}, B_{1}^{B_{2}}, C_{1}^{B_{2}}\right)$ and of its previous bids $\left(b_{1}^{C_{1}}, b_{1}^{B_{2}}, c_{1}^{B_{2}}\right)$.

Consumption was not included, as it can be deducted mechanically from (9) and (12).

A government strategy is the following. 
1. A tax $T_{1}^{1}$, bids $C_{1}^{B_{1}}, B_{2}^{C_{1}}$ and a price $P_{B_{1} B_{2}}$.

2. A tax $T_{2}$ as a function of the previous actions taken by the government $\left(T_{1}^{1}, P_{B_{1} B_{2}}, C_{1}^{B_{1}}, B_{2}^{C_{1}}\right)$ and by households $\left(B_{1}^{C_{1}}, B_{1}^{B_{2}}, C_{1}^{B_{2}}\right)$. The actions taken by each individual household are unobservable (except to the household itself); only their aggregates are common knowledge.

I dropped $T_{1}^{2}$ and $C_{2}^{B_{2}}$ from the definition of a government strategy: they are determined as a residual by (10) and (13).

When defining an equilibrium, I will always refer to the game with commitment, in which the government strategy is specified ex ante. Given that government preferences are not modelled, I only look at the equilibrium in the subgame after the government has made its (exogenous) choice.

\section{Ricardian and non-Ricardian Strategies in the Game}

It is interesting to study two different cases. In the first case, government spending is identically zero; in this case, the target level of taxes always exceeds spending and there is never a need for the government to raise additional resources through borrowing. ${ }^{19}$ Government debt exists in this case only as an initial condition, and is repaid using the revenues in excess of spending. In the second case, we maintain the assumption that $G_{2}=0$, but we assume that $G_{1}>\bar{T}$ : in the first period, the target level of taxes is insufficient to finance government spending, and the government needs to raise additional resources by borrowing. We do not consider the case in which $G_{2}>\bar{T}$ : this would only be possible if the government started with negative debt $B_{2}$, which we rule out.

The two questions we are interested in answering are the following.

(i) Can the government adhere to its target level of taxes in all contingencies?

(ii) If not, can the government implement its target level of taxes, i.e., can it adopt a strategy that leads to a unique equilibrium outcome in which taxes are at the target level?

\footnotetext{
${ }^{19}$ This analysis could easily be extended to cases in which government spending is positive but below the target level of taxes in both periods.
} 


\subsection{No Government Spending}

Proposition 3 If $G_{1}=G_{2}=0$ and $B_{1}>0$, there exist government strategies in which taxes are $\bar{T}$ in all contingencies. If the government adopts any such strategy, there is a unique sequential equilibrium outcome. ${ }^{20}$ Furthermore, any such strategy achieves the same initial price level $P_{C_{1} B_{1}}$, whereas inflation and hence the price level $P_{C_{2} B_{2}}$ depends on the particular strategy.

The complete proof is in the appendix; I describe here the outline and the intuition. The government strategy sets $T_{1}^{1}=\bar{T}$, and the nominal interest rate $P_{B_{1} B_{2}}$ at any (strictly positive) level. The government bids the entire amount $C_{1}^{B_{1}}=\bar{T}$ in exchange for maturing bonds while it does not submit any bid on the market between goods and new bonds. In period 2, the government levies a tax $T_{2}=\bar{T}$ and uses the revenues to bid $C_{2}^{B_{2}}=\bar{T}$ in exchange for bonds maturing in period 2. It can be immediately verified from the description of the game that these actions can be taken independently of the choices by the households, and that they deliver the target level of taxes in all contingencies, independently of the household actions.

With the given government strategy, there is a unique equilibrium, in which the unit of account (the "dollar") has a well-defined value. As in Cochrane [5], government debt in this example is essentially an entitlement to a future payoff and a "dollar" simply represents a share of the debt; in equilibrium, households will submit bids such that these shares are correctly priced as if they were any other asset.

We want next to establish whether the suggested government strategy is Ricardian. If we write the government budget constraint adapted from (3), we obtain

$$
B_{1}=\bar{T} P_{C_{1} B_{1}}+\frac{\bar{T} P_{C_{2} B_{2}}}{P_{B_{1} B_{2}}}
$$

which only holds at the equilibrium price level. For prices that are out of equilibrium, (15) is violated, so the strategy is non-Ricardian according to the definition in section 2.

\footnotetext{
${ }^{20}$ While I adopt sequential equilibrium as the equilibrium concept here, I never specify beliefs. In all of the equilibria I look at, a household is indifferent among all nodes of an information set and will take the same choice independently of the belief over the specific node the game is at within the information set. For this reason, specifying beliefs would be superfluous.
} 
However, prices only deviate from the equilibrium values when households fail to make their equilibrium bids. There are two types of deviations: in the first type, households fail to redeem part of the debt. As an example, they bid less than $B_{2}$ in the second period, in which case $P_{C_{2} B_{2}}$ decreases and the present value of taxes seems to fall short of the value of debt. This excess is only apparent, for it is the result of many households failing to claim their parts of repayments: if we only count debt that is presented for redemption, the government budget constraint holds. In the second type of deviation, households do not waste any of their debt, but they misallocate $B_{1}$ across the two markets, redeeming too many bonds and rolling over too few or vice versa. Substituting (8), it can be easily verified that (15) always holds for prices that follow this type of deviation; the strategy is "Ricardian" with respect to this type of deviations.

By studying the market structure behind a competitive equilibrium, we are able to see that the government is subject to constraints that must hold in all contingencies and not just in equilibrium: equations (10) and (13). Equation (15) is instead not a true government budget constraint, because it assumes that all of the debt will be redeemed: this is a correct assumption on the equilibrium path, but may be violated out of equilibrium.

\subsection{Variable Government Spending}

In the case discussed above, all of the debt is inherited from the past, and the government is only

setting terms to repay it. We now look at the case in which $G_{1}>\bar{T}$. In this case, the government would like to run a primary deficit in the first period. In the previous example, the government participated in the markets only by buying government debt, which would have otherwise been worthless to the households; in this example, the government needs to buy goods in the first period, and must thus persuade the households to trade resources that are intrinsically valuable to them. For the sake of simplicity, we retain the assumption that $G_{2}=0$.

While the government was able to meet its target level of taxes in all contingencies when spending was less than taxes in both periods, it is trivial to see that this is not possible when target spending exceeds the target level of taxes. No matter what the government strategy is, households have the option of not participating in the markets where goods are traded for future 
bonds. If households do not participate in this market, equation (10) implies $G_{1} \leq T_{1}$. In this case, there is thus no government strategy that includes $T_{1}=\bar{T}$ independently of the history of play. In the environment we study, any rule that unconditionally requires the government to set spending above taxes in any given period is meaningless. This is one of the key results in the paper, and one of the most robust: in any game in which lending is voluntary, it is impossible for the government to unconditionally adhere to a target level of taxes that falls short of spending.

The previous observation seems to defeat the fiscal theory of the price level. In all of the papers that I am aware of, an unconditional path for taxes and spending is assumed. Nonetheless, the following proposition rescues the fiscal theory by showing that the government can adopt a strategy that leads to a unique equilibrium in the game; in such an equilibrium, taxes are at the target level and the price level is uniquely determined by spending and taxes.

Proposition 4 Assume that there exists a competitive equilibrium in which $T_{1}=T_{2}=\bar{T}$ and that $B_{1}>0$. Then the government can commit to a strategy such that the unique outcome of a sequential equilibrium in the subgame following the commitment coincides with such a competitive equilibrium.

The complete proof is contained in the appendix. I present here the outline and the intuition behind the result. Let

$$
\left(\tilde{C}_{1}, \tilde{C}_{2}, \tilde{T}_{1}^{1}, \tilde{T}_{1}^{2}, \bar{T}, \tilde{B}_{2}, \tilde{B}_{1}^{C_{1}}, \tilde{B}_{1}^{B_{2}}, \tilde{C}_{1}^{B_{2}}, \tilde{B}_{2}^{C_{2}}, \tilde{C}_{1}^{B_{1}}, \tilde{B}_{2}^{B_{1}}, \tilde{B}_{2}^{C_{1}}, \tilde{C}_{2}^{B_{2}}\right)
$$

be the competitive equilibrium allocation and let the associated price system be

$$
\left(\tilde{P}_{C_{1} B_{1}}, \tilde{P}_{B_{1} B_{2}}, \tilde{P}_{C_{1} B_{2}}, \tilde{P}_{C_{2} B_{2}}\right)
$$

A government strategy that achieves the desired result is the following. In period 1, the government sets $T_{1}^{1}=\tilde{T}_{1}^{1}$. It bids $\tilde{C}_{1}^{B_{1}}$ units of goods in exchange for maturing bonds and $\tilde{B}_{2}^{C_{1}}$ units of new bonds in exchange for goods, and sets the nominal interest rate at $\tilde{P}_{B_{1} B_{2}}$. The second installment of taxes $T_{1}^{2}$ is set so that (10) holds; this installment depends thus on the household bid $C_{1}^{B_{2}}$. Independently of what happened in period 1 , the government sets taxes at $\bar{T}$ and bids $\tilde{C}_{2}^{B_{2}}=\bar{T}$ in exchange for bonds maturing in period 2 ; it follows that $G_{2} \equiv 0$. 
The key difference between this strategy and the usual statement of the fiscal theory of the price level is the description of the consequences of a "debt crisis". A debt crisis occurs when households, for any (possibly irrational) reason, refuse to lend to the government or are willing to lend less than the computed equilibrium implies. In the standard description of the fiscal theory, the government does not even need to contemplate this occurrence, and should simply restate its commitment to the exogenous sequence of taxes and spending; no such crisis is even thinkable if the commitment is credible. On the contrary, the strategy I outline above forces the government to increase its taxes in response to a debt crisis; in such an occurrence, not enough resources would be available to pursue the original plan. However, the current increase in taxes today is not matched by a future reduction, so the onset of a debt crisis would be accompanied by an increase in the amount of resources that are offered in repayment of debt and hence an

increase in the rate of return of government debt. As a consequence, any rational household would respond to a debt crisis by lending the government more, rather than less, which ensures that no such crisis can occur in an equilibrium.

\section{An Infinite-Horizon Economy}

The extension of the results derived above to a multiperiod economy is straightforward. It is particularly interesting to extend the analysis to infinite-horizon economies, which allows us to discuss the role of the transversality condition in more detail.

The flow budget constraint of the government in an infinite-horizon economy becomes

$$
P_{t} G_{t}=P_{t} T_{t}+\frac{B_{t+1}}{R_{t}}-B_{t}, \quad t=1,2, \ldots
$$

Unlike in the finite-horizon case, the sequence of flow budget constraints does not imply that the intertemporal budget constraint is satisfied; for this to happen, the sequence of taxes and debt that is offered must also satisfy the transversality condition

$$
\lim _{t \rightarrow \infty} B_{t} \prod_{s=1}^{t-1} \frac{1}{R_{s}}=0
$$


Given a sequence of taxes, spending and prices, it is now always possible to find a sequence of government debt that satisfies the flow budget constraint in any period. A generic sequence of taxes, spending and prices will however imply a sequence of debt that violates the transversality condition. It is frequent for advocates of the fiscal theory to view the flow budget constraint (18) as a constraint that binds the government in all contingencies, whereas the transversality condition (19) is regarded as an equilibrium condition that ensures that bonds are not in excess supply. This position is expressed e.g. in Woodford [22]. In an infinite-horizon economy, a policy rule is thus called Ricardian if it satisfies the transversality condition independently of the sequence of prices, and non-Ricardian otherwise. ${ }^{21}$

We assume now that the household preferences are described by

$$
\sum_{t=0}^{\infty} \beta^{t} u\left(c_{t}\right)
$$

where $\beta<1$ and $u$ satisfies the same properties as in the two-period economy. For convenience, we also assume that $\lim _{c \downarrow 0} u(c)=-\infty$ and that $\lim _{c \rightarrow+\infty} u(c)=K<+\infty$. $^{22}$

The results we obtain for a two-period economy extend to the infinite-horizon case with few qualifications. Throughout all of these propositions, we assume that government spending and

\footnotetext{
${ }^{21}$ Although the transversality condition is analogous to our earlier equation $B_{3}=0$, the argument that it is only a requirement of market clearing can be cast in a more credible way in the infinite-horizon economy. The key difference is that in the two-period economy the value of a bond that matures in period 3 can be 0 without triggering excess demand (since there is no period 3, the bonds are worthless). At that price, the government flow budget constraint implies its transversality condition. The same does not happen in an infinite-horizon economy: a 0 price of bonds in any period would trigger excess demand, and at all strictly positive sequences (19) does not follow from (18). For these sequences, it is argued that the government can meet its flow budget constraint by offering bonds, that are however in excess supply, since households will not buy an amount of bonds that violates the transversality condition. This argument improperly mixes a market clearing concept that could be appropriate in an economy where all trade happens at time 0 with a budget constraint that is appropriate in an economy in which trade takes place over time. In an economy in which all trade happens at time 0 , the government would not supply bonds, but would exchange goods at different dates and contingencies, and the transversality condition would hold.

${ }^{22}$ The introduction of a discount factor is important; to obtain our results, it is necessary that the present value of the current and future endowment be finite at the equilibrium prices. The auxiliary assumptions on $u$ are only needed to streamline proofs, and do not play an important role in the results.
} 
debt repayment in each period is bounded away from the total endowment, i.e., $\exists \bar{G}: G_{t}+\tilde{C}_{t}^{B_{t}} \leq$ $\bar{G}<1 \forall t .23$

Proposition 5 Assume that there exists a competitive equilibrium in which $T_{t}=\bar{T} \forall t \geq 1$. Then the government can commit to a strategy such that, in the subgame following the government commitment:

(i) a Nash equilibrium exists;

(ii) the given competitive equilibrium is the outcome of all Nash equilibria, i.e., it is the unique equilibrium outcome. ${ }^{24}$

Proposition 6 Assume that there exist competitive equilibria in which $T_{s}=\bar{T} \forall s \geq t$ for any economy that starts at time $t \geq 1$ with any distribution of nominal government debt among the households. Then the government can commit to a strategy such that, in the subgame that follows the commitment:

(i) a sequential equilibrium exists;

(ii) the (unique symmetric) competitive equilibrium for the economy starting in period 1 with an equal distribution of debt and the specified sequence of taxes is the outcome of all Nash (and hence of all sequential) equilibria.

Proposition 7 Under the assumptions of proposition 5, if $G_{t} \leq \bar{T} \forall t$, there exists a strategy in which the government commits to raise exactly $\bar{T}$ in every period in all contingencies. If there is some period $t_{0}$ for which $G_{t_{0}}>\bar{T}$, there is no government strategy that implies $T_{t}=\bar{T} \forall t$ in all contingencies.

\footnotetext{
${ }^{23}$ This is another strong sufficient condition that could be relaxed significantly, at the cost of making proofs much more cumbersome.

${ }^{24}$ In this proposition and the next, uniqueness refers to the paths of consumption, prices and taxes, and debt at the beginning of each period. Bids are uniquely determined only if they are symmetric; as we already observed, there are redundant markets and the distribution of bids across those markets among different households cannot be uniquely pinned down.
} 
The proofs and a more complete description of the infinite-horizon game are relegated to the appendix.

The propositions confirm the following two key results that we obtained in the preceding section.

(i) The government can play a strategy in which the price level is uniquely determined by spending and the target level of taxes; the initial price level satisfies

$$
\frac{u^{\prime}\left(1-G_{1}\right)\left[B_{1}+\sum_{s=1}^{\infty} \tilde{B}_{s+1}^{C_{s}}\left(\frac{1}{\prod_{j=1}^{s} \tilde{P}_{B_{j} B_{j+1}}}\right)\right]}{P_{C_{1} B_{1}}}=\sum_{s=1}^{\infty} \beta^{s-1} u^{\prime}\left(1-G_{s}\right) \tilde{C}_{s}^{B_{s}} .
$$

The numerator on the left-hand side is the nominal value of all bonds outstanding and all of the bonds that the government will issue in exchange for goods (fresh borrowing), discounted at the nominal interest rate; the right-hand side is the real value of all repayments to bondholders that the government will make. In a standard government budget constraint, such as (3), only net debt flows appear. Equation (21), which is based on the actual trading strategy the government adopts on the markets in which it participates, keeps the gross flows into and out of the debt stock explicit, emphasizing what the government can control directly (new issues of bonds and the amount of goods it repays to bondholders). In this modified version, equation (21) is an equilibrium condition and not a constraint upon the government behavior, as emphasized by the fiscal theory of the price level.

(ii) Unless taxes always exceed spending, the government cannot set a fixed and exogenous level of surplus/deficit in each period and maintain it in all contingencies, as it is assumed by all of the papers on the fiscal theory of the price level. An unexpected shortfall in revenues from borrowing must be covered through additional taxes.

By making the timing of moves explicit, the game-theoretic description of the economy convincingly shows that the transversality condition plays no special role in our analysis. Both in the finite- and infinite-horizon economy, the crucial issue the government is facing is whether households will be willing to lend the "right" amount of resources in exchange for debt. This 
is a problem that the government faces in any period and that requires an immediate reaction, independently of whether the economy will last a finite or infinite number of periods. The notion that the government could solve the shortfall by issuing additional unbacked debt at out-ofequilibrium prices is simply flawed. The transversality condition only plays a role in determining the households' willingness to purchase the debt in equilibrium, just as the two-period-horizon counterpart $B_{3}=0$ does.

\section{Money}

The most interesting extension of this analysis is the explicit introduction of money. This would allow a comparison with a standard monetarist model in which the price level is essentially determined by the quantity of nominal balances in the economy.

Money could be introduced by modelling explicitly trades among households and ruling out some barter exchanges, therefore creating a "cash-in-advance" constraint.

In any model that encompasses money, the relative price of money and nominal debt would

play a prominent role. Buiter [2] argues that the true consequence of attempting to follow a non-Ricardian policy regime would be an explicit default on debt, so that the relative price of money and currently maturing nominal debt would not be 1 . However, under an interest rate peg the government can use its unlimited ability to supply both new bonds and money to peg the prices in two markets: it will be able to control both the relative price of new bonds and money (the nominal interest rate) and the relative price of maturing bonds and money (at 1). Buiter's criticism is thus more likely to bite when money supply rules are considered, rather than interest-rate rules.

\section{Conclusion}

While this research is unlikely to lay to rest the dispute on the validity of the fiscal theory of the price level, it shows how the question can at least be cast in a more complete model in which the definition of an equilibrium is not controversial. 
In this paper, I show that the usual version of the government budget constraint is not adequate to describe the restrictions on the government policy out of equilibrium. Nonetheless, the government does face budget constraints on its actions even out of equilibrium; the policy rules postulated by proponents of the fiscal theory violate these constraints and are thus misspecified.

I rescue the fiscal theory by displaying a strategy in which the fiscal side of the economy determines the price level in an environment in which the traditional monetarist analysis would imply indeterminacy. This strategy is very much in the spirit of the fiscal theory of the price level: the government guarantees a stream of real payments to the current holders of debt independently of the current or future price level. 


\section{A Proof of proposition 3}

I solve the household's problem backwards.

When submitting its bid in period 2, each household inherits as a given its previous consumption $c_{1}$ and its level of nominal bonds $b_{2}$. At this stage, the household can only choose how much of $b_{2}$ to bid in exchange for additional period-2 goods; the price it expects on that market is given by (11), which is a strictly positive number and is independent of its bid (assuming $\left.B_{2}>0\right)$. The household will thus bid all of its $b_{2}$ bonds and consume $c_{2}=1-T_{2}+\frac{b_{2}^{C_{2}}}{P_{C_{2} B_{2}}}$.

In period 1, the household has to submit 3 bids. Given that the government does not offer new bonds in exchange for goods, the household expects a price $P_{C_{1} B_{2}}=0$, so it will choose $c_{1}^{B_{2}}=0$. The household is thus left with the problem to allocate the initial amount of bonds $b_{1}$ between the bid for new bonds and that for goods. From the perspective of an individual household, each unit bid for goods yields $1 / P_{C_{1} B_{1}}$ units of the consumption good, and each unit bid for new bonds yields $P_{B_{1} B_{2}}$ units of new bonds. While $P_{C_{1} B_{1}}$ is not known to the household ex ante, in equilibrium the household has perfect foresight about it. The household also knows that each unit of new bonds will fetch $1 / P_{C_{2} B_{2}}$ units of period-2 goods. Its problem becomes thus exactly (14). The mechanism I designed corresponds to a Walrasian economy from the perspective of each household: each household is simply taking prices as given and maximizing by allocating its resources. ${ }^{25}$ While mathematically the problem is identical, conceptually a household faces a more-complex problem in the economy I consider: it has to form beliefs not only about future prices, as in a dynamic Walrasian equilibrium, but also about current prices, which are determined only after the bid has been submitted.

\footnotetext{
${ }^{25}$ There is no market for private debt, which makes households borrowing constrained; this is irrelevant in my setup with identical households.
} 
The first-order condition for household bids at an interior yields: ${ }^{26}$

$$
u^{\prime}\left(c_{1}\right)=\frac{P_{B_{1} B_{2}} P_{C_{1} B_{1}} u^{\prime}\left(c_{2}\right)}{P_{C_{2} B_{2}}}
$$

which is the standard Euler equation, together with $B_{1}^{C_{1}}+B_{1}^{B_{2}}=B_{1}$.

An equilibrium in the subgame in which the government strategy is specified, as above, by $T_{1}=\bar{T}, C_{1}^{B_{1}}=\bar{T}, B_{2}^{C_{1}}=0, B_{B_{1}}^{2}=\bar{B}, T_{2} \equiv \bar{T}, C_{2}^{B_{2}} \equiv \bar{T}$ is characterized as follows. From the government strategy, $\frac{B_{2}^{C_{2}}}{P_{C_{2} B_{2}}}=\bar{T}$ after any history. From the government strategy, (11) and (12) we obtain $C_{2}=1$ independently of the household bids. Notice that this is a result on $C_{2}$, which is average consumption; in principle, each household could consume more or less than 1. Similarly, the government strategy, (8) and (9) imply $C_{1}=1$ independently of the history. Using $C_{1}=C_{2}=1$, we see from (22) that inflation is equal to the nominal interest rate chosen by the government. This is because consumption is constant and there is no discount factor, so the real interest rate must be 0 .

We can solve for the bids and the initial price using (8), (11), $B_{1}^{C_{1}}+B_{1}^{B_{2}}=B_{1}$ and $B_{2}=$ $B_{1}^{B_{2}} P_{B_{1} B_{2}}$, from which we obtain $B_{1}^{C_{1}}=B_{1}^{B_{2}}=1 / 2$. The initial equilibrium price is $P_{C_{1} B_{1}}=$ $\frac{B_{1}}{2 T}$ : it is uniquely determined and is independent of the nominal interest rate chosen by the government. QED.

\section{B Proof of proposition 4}

Let

$$
\left(\tilde{C}_{1}, \tilde{C}_{2}, \tilde{T}_{1}^{1}, \tilde{T}_{1}^{2}, \bar{T}, \tilde{B}_{2}, \tilde{B}_{1}^{C_{1}}, \tilde{B}_{1}^{B_{2}}, \tilde{C}_{1}^{B_{2}}, \tilde{B}_{2}^{C_{2}}, \tilde{C}_{1}^{B_{1}}, \tilde{B}_{2}^{B_{1}}, \tilde{B}_{2}^{C_{1}}, \tilde{C}_{2}^{B_{2}}\right)
$$

be the competitive equilibrium allocation and let the associated price system be

$$
\left(\tilde{P}_{C_{1} B_{1}}, \tilde{P}_{B_{1} B_{2}}, \tilde{P}_{C_{1} B_{2}}, \tilde{P}_{C_{2} B_{2}}\right)
$$

\footnotetext{
${ }^{26}$ In equilibrium, households must be choosing an interior point when allocating maturing bonds to the 2 markets. If this were not the case, there would be one period in which goods are offered in exchange for maturing bonds, but no bonds are redeemed; it would then be enough to bid an arbitrarily small amount to obtain the goods essentially for free.
} 
We prove the proposition for the case in which the government participates in all markets: $\left(\tilde{C}_{1}^{B_{1}}, \tilde{B}_{2}^{C_{1}}\right) \gg 0$. The proof of the other cases is analogous, except that prices are not defined in the markets in which the government does not participate; in those markets, households (correctly) expect any bid they submit to be wasted, and hence in equilibrium they would not submit bids.

Consider the following government strategy. In period 1 , the government sets $T_{1}^{1}=\tilde{T}_{1}^{1}$. It bids $\tilde{C}_{1}^{B_{1}}$ units of goods in exchange for maturing bonds and $\tilde{B}_{2}^{C_{1}}$ units of new bonds in exchange for goods, and sets the nominal interest rate at $\tilde{P}_{B_{1} B_{2}}$. The second installment of taxes $T_{1}^{2}$ is set so that (10) holds; this installment depends thus on the household bid $C_{1}^{B_{2}}$. Independently of what happened in period 1 , the government sets taxes at $\bar{T}$ and bids $\tilde{C}_{2}^{B_{2}}=\bar{T}$ in exchange for bonds maturing in period 2 ; it follows that $G_{2} \equiv 0$.

We now look at the household response if the government commits to the strategy above. In period 2, households will bid all of their maturing bonds against goods, independently of the previous history, so for each household $b_{2}^{C_{2}}=b_{2}$ and in the aggregate $B_{2}^{C_{2}}=B_{2}$, independently of the previous history. In a competitive equilibrium in which $G_{1}>T_{1}$ it is necessarily the case that $B_{2}>0$ and $T_{2}>0$, so we know $\tilde{B}_{2}>0$ and hence $\tilde{P}_{C_{2} B_{2}} \in(0,+\infty)$.

Each household has beliefs about the bids that will be submitted by the others, and uses (8) and (11) to get a belief about the prices that will arise in each trading post. Given its beliefs about prices, the household solves (14). In a symmetric equilibrium, the solution to (14) must coincide with the belief that the household has about the behavior of other households.

In a symmetric equilibrium, the bids submitted by the households can be derived from the following requirements.

(i) First-order conditions for (14):

$$
\begin{aligned}
& \frac{u^{\prime}\left(C_{1}\right)}{P_{C_{1} B_{1}}}=u^{\prime}\left(1-\bar{T}+B_{2} P_{C_{2} B_{2}}\right) \frac{P_{B_{1} B_{2}}}{P_{C_{2} B_{2}}}+\mu, \\
& \mu \geq 0 \text { if } B_{1}^{C_{1}}>0, \quad \mu \leq 0 \text { if } B_{1}^{C_{1}}<B_{1} \\
& u^{\prime}\left(C_{1}\right)=u^{\prime}\left(1-\bar{T}+B_{2} P_{C_{2} B_{2}}\right) \frac{P_{C_{1} B_{2}}}{P_{C_{2} B_{2}}}+\nu, \\
& \nu \geq 0 \text { if } C_{1}^{B_{2}}<1-T_{1}^{1}, \quad \nu \leq 0 \text { if } C_{1}^{B_{2}}>0
\end{aligned}
$$




$$
\begin{aligned}
C_{1} & =1-T_{1}+\frac{B_{1}^{C_{1}}}{P_{C_{1} B_{1}}}-C_{1}^{B_{2}} \\
B_{1}^{C_{1}}+B_{1}^{B_{2}} & =B_{1} \\
B_{2} & =B_{1}^{B_{2}} P_{B_{1} B_{2}}+C_{1}^{B_{2}} P_{C_{1} B_{2}}
\end{aligned}
$$

where $\mu$ and $\nu$ are Kuhn-Tucker multipliers;

(ii) Equations (8) and (11), which describe the price formation at the trading posts.

(iii) The decisions to which the government is committed:

$$
\begin{aligned}
& T_{1}^{1}=\tilde{T}_{1}^{1} \\
& P_{B_{1} B_{2}}=\tilde{P}_{B_{1} B_{2}} \\
& B_{2}^{C_{1}}=\tilde{B}_{2}^{C_{1}} \\
& C_{1}^{B_{2}}=\tilde{C}_{1}^{B_{2}} \\
& C_{2}^{B_{2}}=\tilde{C}_{2}^{B_{2}}=\bar{T}
\end{aligned}
$$

(iv) The government budget constraint

$$
T_{1}=T_{1}^{1}+T_{1}^{2}=G_{1}-C_{1}^{B_{1}}+C_{1}^{B_{2}}
$$

The allocation and price system in (16) and (17) form a competitive equilibrium, which implies that equations (23), (24), (25), (8), (11), (26) and (27) must hold. The competitive equilibrium we are considering is thus an equilibrium outcome of the subgame in which the government committed to the strategy above. The household strategy in this equilibrium calls for bidding $\tilde{B}_{1}^{B_{2}}, \tilde{B}_{1}^{C_{1}}$ and $\tilde{C}_{1}^{B_{2}}$ in the first period, and bidding all of the period 2 bonds in the second period independently of the previous history.

We next need to prove that this is the unique symmetric equilibrium. ${ }^{27}$

\footnotetext{
${ }^{27}$ Since the household utility is strictly concave in consumption and the constraint set is weakly convex, any competitive equilibrium has the feature that consumption is the same for all households in all periods, and the same must thus be true for the amount of debt $B_{2}$. Nonsymmetric equilibria only differ by allowing households to submit different bids, that yield the same net trade, on the redundant markets.
} 
Notice that, in an equilibrium, we must have $\mu \leq 0$ and $\nu \leq 0$. If $\mu$ were greater than 0 , equation (23) implies that households would not be bidding maturing bonds in exchange for goods. In this case, a single household could capture the entire government bid of goods by submitting an arbitrarily small bid on the market shunned by all others: it would face an arbitrarily favorable price on that market, which would contradict the optimality of not submitting a bid. Similarly, we have $\nu \leq 0$ : since the government is offering new bonds in exchange for goods, households must be submitting strictly positive bids on that market.

There are thus four cases, depending on whether either constraint is binding. In all four cases, repeated substitution shows that there exists a unique solution to the system of equations (23), (24), (25), (8), (11), (26) and (27), which yields the desired result. QED.

It is worth noticing that, in the more natural case in which $\mu=0$ and $\nu=0,(23)$ and (24) imply

$$
P_{B_{1} B_{2}}=P_{C_{1} B_{2}} / P_{C_{1} B_{1}}
$$

This relationship stems from the fact that, from the perspective of a single household, this economy has redundant markets. The same consumption vector can be achieved either by rolling some debt over or by redeeming it for goods while at the same time purchasing new bonds with goods. In equilibrium, a household must be indifferent between the two strategies in order to participate in all markets, and this links the prices on the 3 markets that are open in period $1 .{ }^{28}$

\section{The Infinite-Horizon Economy and Proof of Proposi- tions 5-7}

As in the two-period economy, we keep the assumption of a unit endowment of the consumption good in each period.

Each household starts the first period with $B_{1}$ units of government bonds; we continue to study an economy with only one-period debt.

\footnotetext{
${ }^{28}$ Equation (28) is analogous to a no-arbitrage condition, but arbitrage is precluded in this environment because households cannot sell goods or assets short.
} 
The government must finance an exogenous sequence of spending $\left\{G_{t}\right\}_{t=1}^{\infty}$. Lump-sum taxes are denoted by $T_{t}$.

Households have preferences given by (20).

We now describe the sequence of actions within each period $t=1,2, \ldots$. Since there is no longer a last period, the same number of markets (three) is now open in each period.

(i) Each household starts with 1 unit of the period- $t$ good and $b_{t}$ units of government debt maturing in period $t$. While in equilibrium all households will have the same amount of bonds, in principle $b_{t}$ may vary from household to household. The government levies a first installment of period- $t$ taxes, $T_{t}^{1} \in[0,1]$ and sets a price $P_{B_{t} B_{t+1}}$ at which it stands ready to exchange maturing bonds for new bonds. The government submits a sale bid for $C_{t}^{B_{t}}$ units of goods in the market for maturing bonds, subject to $C_{t}^{B_{t}} \leq T_{t}^{1}$. It also submits a sale bid for $B_{t+1}^{C_{t}}$ units of new bonds in exchange for goods.

(ii) Trading opens. Each household may submit a sale bid for $b_{t}^{C_{t}}$ units of bonds in the market for goods, and another sale bid for $b_{t}^{B_{t+1}}$ units of bonds in the market for new bonds maturing next period, subject to the constraint that $b_{t}^{C_{t}}+b_{t}^{B_{t+1}} \leq b_{t}$. Each household may also submit a sale bid of $c_{t}^{B_{t+1}}$ units of goods in exchange for new bonds, subject to the constraint that $c_{t}^{B_{t+1}} \leq 1-T_{t}^{1}$.

(iii) For the markets in which the price is not set by the government, the ratio of the quantities of the unconditional bids sets the price and exchange takes place. The government meets the demand of new bonds in the market in which it sets the price. We thus have

$$
\begin{aligned}
P_{C_{t} B_{t}} & =\frac{B_{t}^{C_{t}}}{C_{t}^{B_{t}}} \\
P_{C_{t} B_{t+1}} & =\frac{B_{t+1}^{C_{t}}}{C_{t}^{B_{t+1}}} \\
B_{t+1}^{B_{t}} & =B_{t}^{B_{t+1}} P_{B_{t} B_{t+1}}
\end{aligned}
$$

As before, $P_{C_{t} B_{t}}$ is the price level of this economy and $P_{B_{t} B_{t+1}}$ is the nominal interest rate. For technical reasons, I assume that there is a limit $\bar{B}_{t}$ to the amount of debt that each household can carry into the following period. I assume that any amount in excess of $\bar{B}_{t}$ 
gets lost. The only role of this assumption is to prevent a set of households of measure 0 from owning a positive measure of debt. $\bar{B}_{t}$ can arbitrarily depend on time and the past history of play. This upper bound is completely unrelated to the transversality condition of the government: $\bar{B}_{t}$ could grow at any exponential rate, or even faster, so that a household that held debt in the amount $\bar{B}_{t}$ (if at all possible) would be violating its transversality condition.

(iv) The government levies a second installment of taxes (or transfers) $T_{t}^{2} \in\left[-T_{t}^{1}+C_{t}^{B_{t}}-\right.$ $\left.B_{t+1}^{C_{t}} P_{C_{t} B_{t+1}}, 1-T_{t}^{1}+C_{t}^{B_{t}}-C_{t}^{B_{t+1}}\right]$. As in section 3 , we need to specify the consequences a household faces if it cannot meet the tax obligation at this stage. Because I assumed utility is unbounded below, a sufficient penalty is for the government to seize an arbitrarily large fraction of the current endowment of the household in the current period, without imposing any further penalty in the future. As in section 3, any unmet tax obligation is redistributed over the remaining households, and the private sector in the aggregate always has enough resources to meet the required tax payment.

(v) Consumption and government spending take place. Each household consumes

$$
c_{t}=\max \left\{0,1-T_{t}-c_{t}^{B_{t+1}}+\frac{b_{t}^{C_{t}}}{P_{C_{t} B_{t}}}\right\}
$$

where $T_{t}=T_{t}^{1}+T_{t}^{2}$ and starts period $t+1$ with $b_{t+1}=b_{t}^{B_{t+1}} P_{B_{t} B_{t+1}}+c_{t}^{B_{t+1}} P_{C_{t} B_{t+1}}$ units of nominal bonds. The government spends

$$
G_{t}=T_{t}+C_{t}^{B_{t+1}}-C_{t}^{B_{t}}
$$

(vi) Period $t$ ends and the economy starts from the first step in period $t+1$.

In order to define strategies, we need a notation that keeps track of the nodes and information sets of the game.

We define the histories of our game as follows.

$$
\begin{aligned}
h_{1}^{g} & =\emptyset \\
h_{t}^{h} & =\left(h_{t}^{g}, T_{t}^{1}, P_{B_{t} B_{t+1}}, C_{t}^{B_{t}}, B_{t+1}^{C_{t}}\right), \quad t=1, \ldots \\
h_{t+1}^{g} & =\left(h_{t}^{h}, \mathbf{b}_{t}^{C_{t}}, \mathbf{b}_{t}^{B_{t+1}}, \mathbf{c}_{t}^{B_{t+1}}\right) t=1, \ldots
\end{aligned}
$$


subject to the following restrictions:

$$
\begin{aligned}
& T_{t}^{1} \in[0,1], t=1, \ldots \\
& P_{B_{t} B_{t+1}} \in \mathbb{R}_{+}, t=1, \ldots \\
& C_{t}^{B_{t}} \in\left[0, T_{t}^{1}\right], t=1, \ldots \\
& B_{t+1}^{C_{t}} \in \mathbb{R}_{+}, t=1, \ldots \\
& \mathbf{b}_{t}^{C_{t}}:[0,1] \rightarrow \mathbb{R}_{+}, t=1, \ldots \\
& \mathbf{b}_{t}^{B_{t+1}}:[0,1] \rightarrow \mathbb{R}_{+}, t=1, \ldots \\
& \mathbf{b}_{t}^{C_{t}}(i)+\mathbf{b}_{t}^{B_{t+1}}(i) \leq \mathbf{b}_{t}(i), i \in[0,1], t=1, \ldots \\
& \mathbf{b}_{1}(i) \equiv B_{1} \text { given, } i \in[0,1] \\
& \mathbf{b}_{t}(i) \equiv \mathbf{b}_{t-1}^{B_{t}}(i) P_{B_{t-1} B_{t}}+B_{t}^{C_{t-1}} \frac{\mathbf{c}_{t-1}^{B_{t}}(i)}{C_{t-1}^{B_{t}}}, i \in[0,1], t=2, \ldots \\
& C_{t-1}^{B_{t}} \equiv \int_{0}^{1} \mathbf{c}_{t-1}^{B_{t}}(i) d i, i \in[0,1], t=2, \ldots \\
& \mathbf{c}_{t}^{B_{t+1}}(i) \in\left[0,1-T_{t}^{1}\right], i \in[0,1], t=1, \ldots
\end{aligned}
$$

Households are indexed by $i \in[0,1]$, and boldface letters describe the behavior of each household. For obvious technical reasons, the game only looks at histories in which all of the boldface functions are measurable.

In section 3, we defined a competitive equilibrium for the economy starting at time 1 . Here, it will be useful to define a competitive equilibrium for an economy that starts at any time $t$ and with any distribution of debt holdings given by a (measurable) function $\mathbf{b}_{t}:[0,1] \rightarrow \mathbb{R}_{+}$.

Definition 2 A competitive equilibrium from period $t$ and an initial distribution of debt $\mathbf{b}_{t}$ is an allocation

$$
\left\{\left(\mathbf{c}_{s}, C_{s}, T_{s}^{1}, T_{s}^{2}, \mathbf{b}_{s+1}, B_{s+1}, \mathbf{b}_{s}^{C_{s}}, B_{s}^{C_{s}}, \mathbf{b}_{s}^{B_{s+1}}, B_{s}^{B_{s+1}}, \mathbf{c}_{s}^{B_{s+1}}, C_{s}^{B_{s+1}}, C_{s}^{B_{s}}, B_{s+1}^{B_{s}}, B_{s+1}^{C_{s}}\right)\right\}_{s=t}^{\infty}
$$

and a price system

$$
\left\{\left(P_{C_{s} B_{s}}, P_{B_{s} B_{s+1}}, P_{C_{s} B_{s+1}}\right)\right\}_{s=t}^{\infty}
$$

such that: 
(i) Given prices and taxes, for each $i \in[0,1],\left\{\left(\mathbf{c}_{s}(i), \mathbf{b}_{s+1}(i), \mathbf{b}_{s}^{C_{s}}(i), \mathbf{b}_{s}^{B_{s+1}}(i), \mathbf{c}_{s}^{B_{s+1}}(i)\right\}_{s=t}^{\infty}\right.$ solves the household maximization problem:

$$
\begin{aligned}
& \max _{\left\{\left(c_{s}, b_{s+1}, b_{s}^{C_{s}}, b_{s}^{B_{s}+1}, c_{s}^{B_{s+1}}\right)\right\}_{s=t}^{\infty} \geq \mathbf{0}} \sum_{s=t}^{\infty} \beta^{s-t} u\left(c_{s}\right) \text { s.t. } \\
& c_{s}=\max \left\{0,1-T_{s}^{1}-T_{s}^{2}+\frac{b_{s}^{C_{s}}}{P_{C_{s} B_{s}}}-c_{s}^{B_{s+1}}\right\} \\
& b_{s}^{C_{s}}+b_{s}^{B_{s+1}} \leq b_{s} \\
& b_{s+1}=b_{s}^{B_{s+1}} P_{B_{s} B_{s+1}}+c_{s}^{B_{s+1}} P_{C_{s} B_{s+1}} \\
& c_{s}^{B_{s}} \leq 1-T_{s}^{1} \\
& b_{t}=\mathbf{b}_{t}(i) \text { given by the initial distribution }
\end{aligned}
$$

(ii) At each time, the aggregate bids and consumption correspond to the appropriate average of the individuals' actions, i.e.,

$$
\begin{aligned}
C_{s} & =\int_{0}^{1} \mathbf{c}_{s}(i) d i \\
B_{s+1} & =\int_{0}^{1} \mathbf{b}_{s+1}(i) d i \\
B_{s}^{C_{s}} & =\int_{0}^{1} \mathbf{b}_{s}^{C_{s}}(i) d i \\
B_{s}^{B_{s+1}} & =\int_{0}^{1} \mathbf{b}_{s}^{B_{s+1}}(i) d i \\
C_{s}^{B_{s+1}} & =\int_{0}^{1} \mathbf{c}_{s}^{B_{s+1}}(i) d i
\end{aligned}
$$

(iii) The government's actions satisfy the feasibility requirements in each period:

$$
\begin{gathered}
T_{s}^{1} \in[0,1] \\
C_{s}^{B_{s}} \in\left[0, T_{s}^{1}\right] \\
T_{s}^{2} \in\left[-T_{s}^{1}+C_{s}^{B_{s}}-B_{s+1}^{C_{s}} P_{C_{s} B_{s+1}}, 1-T_{s}^{1}+C_{s}^{B_{s}}-C_{s}^{B_{s+1}}\right]
\end{gathered}
$$

(iv) Markets clear and the government budget constraints hold, i.e. equations (29) and (31) are satisfied for any period $s$. 
Unless a period is explicitly mentioned, by competitive equilibrium we mean a competitive equilibrium for the economy starting in period 1 with a degenerate distribution of debt holdings, $\mathbf{b}_{1}(i)=B_{1} \forall i \in[0,1]$.

Lemma 1 In any competitive equilibrium, no household ever defaults on its tax obligations, provided the penalty for doing so is a sufficiently small consumption level $\epsilon$ during that period.

Proof. We prove this by contradiction. Suppose $\left\{\mathbf{c}_{s}(i)\right\}_{s=t}^{\infty}$ is a competitive equilibrium choice for household $i$, and it involves consuming $\epsilon$ during some periods. Let $s_{0}$ be the first period in which consumption is $\epsilon$. Household $i$ could guarantee itself a consumption plan given by $\left(\left\{\mathbf{c}_{s}(i)\right\}_{s=t}^{s_{0}-1}, 1-G_{s}-\tilde{C}_{s}^{B_{s}}\right)$ simply by not submitting any bid from period $s_{0}$ onwards. Since $1-G_{s}-\tilde{C}_{s}^{B_{s}}$ is bounded away from 0 , utility is unbounded below and bounded above, this alternative consumption stream is necessarily preferable to the supposed equilibrium whenever $\epsilon$ is sufficiently small: the cost of consuming $\epsilon$ today could never be recouped in the future, no matter how large consumption is. QED.

Lemma 1 implies that the solution to the household maximization problem is in the range where the objective function is strictly concave, while the constraints are a weakly convex set. As a consequence, all households will have the same consumption and the same level of assets in all periods.

As we did for the two-period economy, we need to look at government and household strategies to study existence of an equilibrium in the game-theoretic sense and its properties. To do so, it is important to describe what information is available to each player at the moment a choice is made.

The government is called to move after histories of the type $h_{t}^{g}$. However, we assume the government only observes the actions by the households up to sets of measure 0 . Two histories are thus in the same government information set whenever all the functions that describe the past play of private households differ at most by a set of measure 0 . The households move after histories $h_{t}^{h}$; each household $i$ observes its own actions and the actions by all other households in the economy up to measure 0 sets. Two histories are thus in the same information set of household $i$ if all the functions that describe past play of the private households differ at most 
by a set of measure 0 and if they coincide exactly for the point $i .^{29}$

Let $H^{g}$ be the set of histories after which the government moves and $H^{h}$ the set of histories after which households move. A government strategy is a mapping $\sigma^{g}$ from $H^{g}$ to a vector of actions $\left(T_{t}^{1}, P_{B_{t} B_{t+1}}, C_{t}^{B_{t}}, B_{t+1}^{C_{t}}\right)$ such that:

(i) $\sigma^{g}$ assigns the same actions to histories that are in the same information set;

(ii) $\left(T_{t}^{1}, P_{B_{t} B_{t+1}}, C_{t}^{B_{t}}, B_{t+1}^{C_{t}}\right)$ satisfies $(32)$.

A household strategy $\sigma^{i}$ is a mapping from $H^{h}$ to a vector of actions $\left(\mathbf{b}_{t}^{C_{t}}(i), \mathbf{b}_{t}^{B_{t+1}}(i), \mathbf{c}_{t}^{B_{t+1}}(i)\right)$ such that:

(i) $\sigma^{i}$ assigns the same actions to histories that are in the same information set;

(ii) $\left(\mathbf{b}_{t}^{C_{t}}(i), \mathbf{b}_{t}^{B_{t+1}}(i), \mathbf{c}_{t}^{B_{t+1}}(i)\right)$ satisfies $(32)$.

As before, the government strategy is taken as exogenous; we look for equilibria in the game in which the government has committed to a given strategy. Within this game, we now prove propositions 5, 6 and 7 .

Proof of proposition 5. Let

$$
\left\{\left(\tilde{C}_{t}, \tilde{T}_{t}^{1}, \tilde{B}_{t+1}, \tilde{B}_{t}^{C_{t}}, \tilde{B}_{t}^{B_{t+1}}, \tilde{C}_{t}^{B_{t+1}}, \tilde{C}_{t}^{B_{t}}, \tilde{B}_{t+1}^{B_{t}}, \tilde{B}_{t+1}^{C_{t}}\right)\right\}_{t=1}^{\infty}
$$

and

$$
\left\{\left(\tilde{P}_{C_{t} B_{t}}, \tilde{P}_{B_{t} B_{t+1}}, \tilde{P}_{C_{t} B_{t+1}}\right)\right\}_{t=1}^{\infty}
$$

be a competitive equilibrium. We will assume $\tilde{C}_{t}^{B_{t}}>0, \tilde{B}_{t+1}^{C_{t}}>0, \tilde{B}_{t}^{B_{t+1}}>0 \forall t$. The proof can be easily repeated for all other cases, except of course that the equilibrium price will be undefined in markets in which no exchange takes place.

A competitive equilibrium satisfies the following conditions at each time $t$ :

$$
\begin{aligned}
& \frac{u^{\prime}\left(C_{t}\right)}{P_{C_{t} B_{t}}}=\beta \frac{u^{\prime}\left(C_{t+1}\right) P_{B_{t} B_{t+1}}}{P_{C_{t+1} B_{t+1}}}+\mu_{t}, \\
& \mu_{t} \geq 0, \mu_{t}=0 \text { if } B_{t}^{C_{t}}<B_{t}
\end{aligned}
$$

\footnotetext{
${ }^{29}$ Note that two histories in the same information set imply the same feasible action set, both in the case of the government and its information set and in the case of households and their information set.
} 


$$
\begin{gathered}
u^{\prime}\left(C_{t}\right)=\frac{\beta u^{\prime}\left(C_{t+1}\right) P_{C_{t} B_{t+1}}}{P_{C_{t+1} B_{t+1}}}+\nu_{t} \\
\nu_{t} \leq 0 \nu_{t}=0 \text { if } C_{t}^{B_{t+1}}<1-T_{t}^{1} \\
\lim _{t \rightarrow \infty} \beta^{t} u^{\prime}\left(C_{t}\right) \frac{B_{t}}{P_{C_{t} B_{t}}}=0 \\
T_{t}^{2}=G_{t}-T_{t}^{1}+C_{t}^{B_{t}}-C_{t}^{B_{t+1}} \\
B_{t}^{C_{t}}+B_{t}^{B_{t+1}}=B_{t} \\
B_{t+1}=B_{t}^{B_{t+1}} P_{B_{t} B_{t+1}}+C_{t}^{B_{t+1}} P_{C_{t} B_{t+1}} \\
P_{C_{t} B_{t}}=\frac{B_{t}^{C_{t}}}{C_{t}^{B_{t}}} \\
P_{C_{t} B_{t+1}}=\frac{B_{t+1}^{C_{t}}}{C_{t}^{B_{t+1}}} \\
C_{t}=1-G_{t}
\end{gathered}
$$

In what follows, we assume that the Lagrange multiplier $\mu_{t}$ is zero for the competitive equilibrium that we are considering. If this is not the case, then we can construct another price system that is identical to the former except for $P_{B_{t} B_{t+1}}$, which is set such that (35) holds with $\mu_{t}=0$. It is trivial to check that this new price system forms a competitive equilibrium with the same allocation as before. ${ }^{30}$

We consider the following government strategy. At each time $t$, independently of the past history of play, the government chooses the vector $\left(\tilde{T}_{t}^{1}, \tilde{P}_{B_{t} B_{t+1}}, \tilde{C}_{t}^{B_{t}}, \tilde{B}_{t+1}^{C_{t}}\right)$. With this strategy, if $\tilde{B}_{t+1}^{C_{t}}>0$, total tax revenues in period $t$ are $G_{t}+C_{t}^{B_{t}}-C_{t}^{B_{t+1}}$ and depend thus on the actions private households take at time $t$. Intuitively, whenever the government expects to raise revenues through fresh borrowing, taxes must be adjusted if these revenues fall short of (or exceed) the target.

Because there is a continuum of households and the actions of each of them are not observable individually, each household perceives that the future actions by all other players will be

\footnotetext{
${ }^{30}$ Intuitively, if (35) holds with inequality, the government is offering a very unattractive rate of return on rolling over debt, so each household strictly prefers redeeming all of its maturing debt at time $t$. In this case, nothing changes if the government raises the rate of return up to the point at which households still redeem all of their debt at time $t$, but are exactly indifferent at the margin between redeeming it or rolling it over.
} 
unaffected by whatever sequence of actions it takes. As a consequence, each household takes as given the actions of the government and of other households when choosing its moves. In particular, this implies that each household expects a sequence of prices and taxes that follows from everybody else's strategies but is independent of its own actions: therefore, in equilibrium, each household behaves as in a competitive equilibrium and solves (33). For this reason, any outcome of an equilibrium (whether Nash or sequential) must be a competitive equilibrium. In order to prove the proposition, we thus need to prove that there is a unique allocation ${ }^{31}$ and price system that satisfies equations (35)-(43) at all times $t$ together with

$$
\left(T_{t}^{1}, P_{B_{t} B_{t+1}}, C_{t}^{B_{t}}, B_{t+1}^{C_{t}}\right)=\left(\tilde{T}_{t}^{1}, \tilde{P}_{B_{t} B_{t+1}}, \tilde{C}_{t}^{B_{t}}, \tilde{B}_{t+1}^{C_{t}}\right)
$$

Using repeated substitution in the system of equations (35)-(43) and (44), the entire allocation, price system and sequence of taxes can be derived uniquely as a function of the initial price level $P_{C_{1} B_{1}}$. From this system it also follows that

$$
\begin{aligned}
& \beta^{t-1} u^{\prime}\left(1-G_{t}\right) \frac{B_{t}}{P_{C_{t} B_{t}}}= \\
& \frac{u^{\prime}\left(1-G_{1}\right)}{P_{C_{1} B_{1}}}\left[B_{1}+\sum_{s=1}^{t-1} \tilde{B}_{s+1}^{C_{s}}\left(\frac{1}{\prod_{j=1}^{s} \tilde{P}_{B_{j} B_{j+1}}}\right)\right]-\sum_{s=1}^{t-1} \beta^{s-1} u^{\prime}\left(1-G_{s}\right) \tilde{C}_{s}^{B_{s}}
\end{aligned}
$$

We can now use the transversality condition (37) to obtain a unique solution for the initial price level:

$$
P_{C_{1} B_{1}}=\frac{u^{\prime}\left(1-G_{1}\right)\left[B_{1}+\sum_{s=1}^{\infty} \tilde{B}_{s+1}^{C_{s}}\left(\frac{1}{\prod_{j=1}^{s} \tilde{P}_{B_{j} B_{j+1}}}\right)\right]}{\sum_{s=1}^{\infty} \beta^{s-1} u^{\prime}\left(1-G_{s}\right) \tilde{C}_{s}^{B_{s}}}
$$

Notice that the second infinite sum in (21) is always convergent provided $G_{t}$ is bounded away from 1; the first infinite sum must be convergent in order for equation (21) to have a solution. By assumption $\tilde{P}_{C_{1} B_{1}}$ satisfies equation (21), given that it is part of a competitive equilibrium. It thus follows that $\tilde{P}_{C_{1} B_{1}}$ is the unique price level that is consistent with a competitive equilibrium when the government plays the strategy specified above. This price level can then be used to establish uniqueness of the entire allocation and price system, working through the system (35)-(43) and (44) backwards.

\footnotetext{
${ }^{31}$ See footnote 27 .
} 
To prove existence of a Nash equilibrium, we can proceed as follows. The competitive equilibrium we are studying generates a path in the game (i.e., a sequence of histories). Along that path, we set the household strategy $\sigma^{i}, i \in[0,1]$ to the actions prescribed by the competitive equilibrium itself. For all other histories, $\sigma^{i}$ can be set arbitrarily. A Nash equilibrium requires each household's strategy to be a best response to the strategies of all other households (and the government's, which is set ex ante). Since each household knows that its actions will not affect the actions taken by any other household or the government, it is enough for the strategy to be a best response to the actions taken by all other households and the government (along the equilibrium path). In a competitive equilibrium, this is true. QED.

Proof of proposition 6. The key additional step that proposition 6 requires is to prove that there exists a strategy profile that recommends an optimal choice for households (given their beliefs) not just on the equilibrium path, but at any node of the game.

By assumption, a competitive equilibrium exists from any period $t$ and any history $h_{t}^{h}$. A competitive equilibrium describes a path of play in the game from time $t$ on, so it generates a sequence of histories from time $t$ onwards.

The following two observations will be useful.

(i) If $h_{v}^{h}$ is a history generated by a competitive equilibrium

$$
\begin{aligned}
& \left\{\left(\hat{\mathbf{c}}_{s}, \hat{C}_{s}, \hat{T}_{s}^{1}, \hat{T}_{s}^{2}, \hat{\mathbf{b}}_{s+1}, \hat{B}_{s+1}, \hat{\mathbf{b}}_{s}^{C_{s}}, \hat{B}_{s}^{C_{s}}, \hat{\mathbf{b}}_{s}^{B_{s+1}}, \hat{B}_{s}^{B_{s+1}}, \hat{\mathbf{c}}_{s}^{B_{s+1}}, \hat{C}_{s}^{B_{s+1}}, \hat{C}_{s}^{B_{s}}, \hat{B}_{s+1}^{B_{s}}, \hat{B}_{s+1}^{C_{s}},\right.\right. \\
& \left.\left.\quad \hat{P}_{C_{s} B_{s}}, \hat{P}_{B_{s} B_{s+1}}, \hat{P}_{C_{s} B_{s+1}}\right)\right\}_{s=t}^{\infty}
\end{aligned}
$$

then it is straightforward to show that

$$
\begin{aligned}
& \left\{\left(\hat{\mathbf{c}}_{s}, \hat{C}_{s}, \hat{T}_{s}^{1}, \hat{T}_{s}^{2}, \hat{\mathbf{b}}_{s+1}, \hat{B}_{s+1}, \hat{\mathbf{b}}_{s}^{C_{s}}, \hat{B}_{s}^{C_{s}}, \hat{\mathbf{b}}_{s}^{B_{s+1}}, \hat{B}_{s}^{B_{s+1}}, \hat{\mathbf{c}}_{s}^{B_{s+1}}, \hat{C}_{s}^{B_{s+1}}, \hat{C}_{s}^{B_{s}}, \hat{B}_{s+1}^{B_{s}}, \hat{B}_{s+1}^{C_{s}},\right.\right. \\
& \left.\left.\quad \hat{P}_{C_{s} B_{s}}, \hat{P}_{B_{s} B_{s+1}}, \hat{P}_{C_{s} B_{s+1}}\right)\right\}_{s=v}^{\infty}
\end{aligned}
$$

is a competitive equilibrium from $h_{v}^{h}$. In other words, the continuation of a competitive equilibrium is a competitive equilibrium itself, from the appropriate initial conditions.

(ii) Suppose $\hat{h}_{t}^{h}$ and $h_{t}^{h *}$ are two histories that differ only by the actions taken by a measure 0 set $S$ of households. This implies that the two histories are in the same information set for 
all households except those in $S$. Suppose

$$
\begin{aligned}
& \left\{\left(\hat{\mathbf{c}}_{s}, \hat{C}_{s}, \hat{T}_{s}^{1}, \hat{T}_{s}^{2}, \hat{\mathbf{b}}_{s+1}, \hat{B}_{s+1}, \hat{\mathbf{b}}_{s}^{C_{s}}, \hat{B}_{s}^{C_{s}}, \hat{\mathbf{b}}_{s}^{B_{s+1}}, \hat{B}_{s}^{B_{s+1}}, \hat{\mathbf{c}}_{s}^{B_{s+1}}, \hat{C}_{s}^{B_{s+1}}, \hat{C}_{s}^{B_{s}}, \hat{B}_{s+1}^{B_{s}}, \hat{B}_{s+1}^{C_{s}},\right.\right. \\
& \left.\left.\hat{P}_{C_{s} B_{s}}, \hat{P}_{B_{s} B_{s+1}}, \hat{P}_{C_{s} B_{s+1}}\right)\right\}_{s=t}^{\infty}
\end{aligned}
$$

is a competitive equilibrium for the economy after $\hat{h}_{t}^{h}$.

Then we can find a competitive equilibrium for the economy after $h_{t}^{h *}$ in which the price system is the same, and the allocation is the same for all households that are not in $S$. The behavior of a measure 0 set of households has no effect on the determination of prices (41) and (42), nor on the feasible set for government policy, which can thus remain the same. Whenever the price system and the government policy is the same, the same actions will remain optimal for households outside of the set $S$. Households in $S$ will potentially start from a different level of debt after $\hat{h}_{t}^{h}$ than the one they start from after $h_{t}^{h *}$; as a consequence, their optimal actions will be different. For the given price level and government policy, an optimal path of actions for each of these households may be found by solving the (well-defined) maximization problem (33).

Given the previous two observations, it is possible to construct a mapping $f$ from histories of the game into competitive equilibria

$$
\begin{aligned}
& \left\{\left(\mathbf{c}_{s}, C_{s}, T_{s}^{1}, T_{s}^{2}, \mathbf{b}_{s+1}, B_{s+1}, \mathbf{b}_{s}^{C_{s}}, B_{s}^{C_{s}}, \mathbf{b}_{s}^{B_{s+1}}, B_{s}^{B_{s+1}}, \mathbf{c}_{s}^{B_{s+1}}, C_{s}^{B_{s+1}}, C_{s}^{B_{s}}, B_{s+1}^{B_{s}}, B_{s+1}^{C_{s}},\right.\right. \\
& \left.\left.\quad P_{C_{s} B_{s}}, P_{B_{s} B_{s+1}}, P_{C_{s} B_{s+1}}\right)\right\}_{s=t}^{\infty}
\end{aligned}
$$

with the following properties.

(i) If $h_{v}^{h}$ is a history generated by the competitive equilibrium $f\left(h_{t}^{h}\right)$, then $f\left(h_{v}^{h}\right)$ coincides with the elements of $f\left(h_{t}^{h}\right)$ from period $v$ onwards.

(ii) If $\hat{h}_{t}^{h}$ and $h_{t}^{h *}$ are two histories that differ only by the actions taken by a measure 0 set $S$ of households, then $f\left(\hat{h}_{t}^{h}\right)$ and $f\left(h_{t}^{h *}\right)$ are the same except for the actions taken by households in the set $S$. 
We construct the household strategy profile $\sigma^{i}, i \in[0,1]$ by taking the corresponding elements from the mapping $f$. It immediately follows that the strategy profile is adapted to the information available to the household; furthermore, at any node $h_{t}^{h}$, the strategy profile dictates the households to play a competitive equilibrium from there onwards, so the choice of each household is optimal given the expected choices by all other households. Finally, we do not need to know the exact beliefs of each household about the particular node it is in within its information set at any time $t$ : from all nodes in an information set, prices and government policy will be the same. QED.

Proof of proposition 7 . When $G_{t} \leq \bar{T} \forall t$, the government does not need to raise any resources through fresh borrowing. It can thus adopt the following strategy. Independently of previous history of play, the government can set $T_{t}^{1}=\bar{T}, \tilde{C}_{t}^{B_{t}}=\bar{T}-G_{t}, \tilde{B}_{t+1}^{C_{t}}=0$ and $\left\{P_{B_{t} B_{t+1}}\right\}_{t=1}^{\infty}$ to any desired sequence. Any goods that the households bid in exchange for new bonds are wasted, as the government is not participating in that market. We could repeat the steps of the proof of proposition 5 and obtain that this strategy leads to a unique equilibrium outcome.

When $G_{t_{0}}>\bar{T}$, the government needs to borrow resources at time $t_{0}$. However, the amount

of resources raised through borrowing $\left(C_{t_{0}}^{B_{t_{0}+1}}\right)$ depends on the actions of the households, so it is impossible for the government to ensure that $C_{t_{0}}^{B_{t_{0}+1}}=G_{t_{0}}-\bar{T}$ in all contingencies. QED.

\section{References}

[1] Marco Bassetto. Equilibrium and Government Commitment. In progress, University of Minnesota, 2001.

[2] Willem H. Buiter. The Fallacy of the Fiscal Theory of the Price Level. NBER Working Paper, 7302, 1999.

[3] V.V. Chari and Patrick J. Kehoe. Sustainable Plans. Journal of Political Economy, 98(4):783-801, 1990.

[4] Lawrence J. Christiano and Terry J. Fitzgerald. Understanding the Fiscal Theory of the Price Level. NBER Working Paper, 7668, 2000. 
[5] John H. Cochrane. Money as Stock: Price Level Determination with no Money Demand. NBER Working Paper, 7498, 1999.

[6] John H. Cochrane. Long Term Debt and Optimal Policy in the Fiscal Theory of the Price Level. Econometrica, 69(1):69-116, 2001.

[7] William Dupor. Exchange Rates and the Fiscal Theory of the Price Level. Journal of Monetary Economics, 45(3):613-630, 2000.

[8] Milton Friedman and Anna J. Schwartz. A Monetary History of the United States 1867-1960. Princeton University Press, 1963.

[9] Douglas M. Gale. Bargaining and Competition Part I: Characterization. Econometrica, 54(4):785-806, 1986.

[10] Douglas M. Gale. Bargaining and Competition Part II: Existence. Econometrica, 54(4):807818, 1986.

[11] Narayana R. Kocherlakota and Christopher Phelan. Explaining the Fiscal Theory of the Price Level. Federal Reserve Bank of Minneapolis Quarterly Review, 23(4):14-23, 1999.

[12] Eric Leeper. Equilibria under 'Active' and 'Passive' Monetary Policies. Journal of Monetary Economics, 27(1):129-147, 1991.

[13] Eduardo H. Loyo. Three Fiscalist Essays. PhD thesis, Princeton University, 1999.

[14] Bennett T. McCallum. Indeterminacy, Bubbles, and the Fiscal Theory of Price Level Determination. NBER Working Paper, 6456, 1998.

[15] Ariel Rubinstein and Asher Wolinsky. Equilibrium in a Market with Sequential Bargaining. Econometrica, 53(5):1133-1150, 1985.

[16] Thomas J. Sargent. Rational Expectations and Inflation. Harper \& Row, 1986.

[17] Thomas J. Sargent and Neil Wallace. Some Unpleasant Monetarist Arithmetic. Federal Reserve Bank of Minneapolis Quarterly Review, 9(1):15-31, 1985. 
[18] Thomas C. Schelling. The Strategy of Conflict. Harvard University Press, 1960.

[19] Martin Shubik. Commodity Money, Oligopoly, Credit and Bankruptcy in a General Equilibrium Model. Western Economic Journal, 11(1):24-38, 1973.

[20] Christopher A. Sims. A Simple Model for Study of the Determination of the Price Level and the Interaction of Monetary and Fiscal Policy. Economic Theory, 4(3):381-399, 1994.

[21] Nancy L. Stokey. Credible Public Policy. Journal of Economic Dynamics and Control, 15:627-656, 1991.

[22] Michael Woodford. Monetary Policy and Price Level Determinacy in a Cash-in-Advance Economy. Economic Theory, 4(3):345-380, 1994.

[23] Michael Woodford. Price Level Determinacy Without Control of a Monetary Aggregate. Carnegie-Rochester Conference Series on Public Policy, 43:1-46, 1995.

[24] Michael Woodford. Control of the Public Debt: A Requirement for Price Stability? In Guillermo Calvo and Mervyn King, editors, The Debt Burden and Monetary Policy, pages 117-154. Macmillan Press, 1998.

[25] Michael Woodford. Doing without Money: Controlling Inflation in a Post-Monetary World. Review of Economic Dynamics, 1:173-219, 1998.

[26] Michael Woodford. Public Debt and the Price Level. Mimeo, Princeton University, 1998. 